\section{Infección por Bartonella henselae: utilidad de las imágenes en el diagnóstico y seguimiento}

\author{
M. Fernanda Tapia, Reinaldo Rosas, \\ Giancarlo Schiappacasse y Luis Thompson
}

\section{Bartonella henselae infection, the importance of images for diagnosis and follow-up}

Bartonella henselae infection is a frequent zoonosis from the domestic cat. It is presented with regional lymphadenitis in the majority of cases. Searching and characterization of lymph nodes by diagnostic imaging can be useful in the differential diagnosis approach, with a clear advantage, because it is a noninvasive method. Currently, new diagnostic imaging techniques improves the quality of screening and characterization of adenopathies, such is the case of PET/CT, which allows a better evaluation of hypermetabolic lymph nodes, without considering the individual growth of each lymph node. In this article, three cases of cat scratch diseases serology and their respective imaging findings are reviewed.

Key words: Cat scratch disease; ultrasonography; computed tomography; positron emission tomography.

Palabras clave: Enfermedad por arañazo de gato; ecografía; tomografía computarizada; tomografía por emisión de positrones.

\section{Introducción}

L a infección por Bartonella henselae es una zoonosis cuyo principal reservorio es el gato doméstico ${ }^{1}$, llegando a una prevalencia de $85 \%$ en los felinos estudiados en tres ciudades de Chile ${ }^{2}$. Las manifestaciones clínicas típicas son la linfadenopatía regional acompañada de fiebre y malestar general. Las localizaciones más frecuentes de las adenopatías son axilares, inguinales, cervicales. Las adenopatías intra-abdominales han sido escasamente documentadas ${ }^{3}$.

Las formas diseminadas ocurren en $5 \%$ de los casos, que incluyen el compromiso hepatoesplénico, óseo, neurológico.

El diagnóstico se basa en antecedentes epidemiológicos y clínicos, pero en los casos de presentaciones atípicas y ausencia de contacto epidemiológico es difícil plantear el diagnóstico. En estos casos, el enfrentamiento diagnóstico supone un desafío y la imagenología puede aportar elementos de juicio para el médico clínico 4 .

El estudio imagenológico de las adenopatías incluye sus características estructurales, el número y la distribución. El tamaño del linfonodo es la

Universidad del Desarrollo/Clínica Alemana de Santiago. Facultad de Medicina

Recibido: 21 de noviembre de 2016 / Aceptado: 25 de abril de 2017

Sin conflicto de interés

Sin fuente de financiamiento.

Correspondencia a:

M. Fernanda Tapia

mariafern.tc@gmail.com característica más importante (mayor a $10 \mathrm{~mm}$ ), si son localizadas o difusas, o si es única o múltiples ${ }^{5}$. La ecografía se utiliza como estudio inicial de las adenopatías superficiales, teniendo poca utilidad en la evaluación de adenopatías intra-abdominales debido a la interferencia de las asas intestinales. La tomografía computarizada (TC) es un buen método diagnóstico, permitiendo una buena evaluación de los órganos intra-abdominales como el hígado y el bazo. Sin embargo, respecto a los linfonodos presenta sus limitaciones, ya que sólo detecta los de mayor tamaño, dejando fuera aquellos ganglios sin crecimiento o lesiones que se localizan en estructuras poco distensibles como el hueso. La tomografía por emisión de positrones (PET/CT, por su sigla en inglés) con fluorodesoxiglucosa marcada permite la evaluación de lesiones hipermetabólicas de manera independiente de su tamaño o lugar. Además se combina la técnica de radioisótopos con la TC, logrando correlacionar con la anatomía y localización de las lesiones. Es de mayor utilidad en ganglios $u$ otras estructuras poco habituales que no presentan alteraciones de tamaño ni estructura ${ }^{5}$.

\section{Casos clínicos}

\section{Caso 1}

Varón de 68 años sin antecedentes mórbidos, procedente de un sector rural de la Región del Bío-Bío. Sin antecedente claro de contacto con gatos. Consultó por cuadro de cinco días de evolución de fiebre de 38 ${ }^{\circ} \mathrm{C}$, epigastralgia urente irradiada al hipocondrio izquierdo, sin diarrea ni vómitos. Los exámenes de laboratorio mostraron una PCR $159 \mathrm{mg} / \mathrm{L}$ y un hemograma sin anemia ni leucocitosis. Se realizó una TC abdominopélvica que evidenció adenopatías en el hilio hepático, tronco celíaco y mediastino. Por sospecha de una enfermedad linfoproliferativa se realizó un PET/CT que mostró adenopatías hipermetabólicas en el tórax, hilio hepático, retroperitoneo, hígado, bazo y fémur derecho. Se realizaron serologías para VEB y CMV que fueron negativas. La IgG para $B$. henselae fue positiva en títulos muy elevados $(1: 10.000)$. Se realizó una biopsia de un ganglio inguinal que se informó como un granuloma necrosante. Se trató con azitromicina presentando una mejoría clínica y remisión de las lesiones hipermetabólicas en la PET/CT (Figura 1).

\section{Caso 2}

Mujer de 59 años, hipertensa, dueña de un gato con un año de edad. Presentó un rasguño en su pierna izquierda, asociado a una adenopatía inguinal izquierda dolorosa, de 2-3 cm de diámetro. La ecografía de tejidos blandos concluyó la presencia de un linfonodo aumentado de tamaño, y otros pequeños de similares características a su alrededor. Se solicitó una IgG para $B$. henselae que resultó positiva (1:512), con pruebas de laboratorio general normales. La PET/CT informó un conglomerado de adenopatías hipermetabólicas inguinales y en la cadena ilíaca. Fue tratada con azitromicina con remisión completa de adenopatías (Figura 2).

\section{Caso 3}

Mujer de 28 años, con antecedente de viaje a Europa, África, Sudeste asiático y Oceanía por 8 meses. Tras su llegada presentó un síndrome febril catalogado como un síndrome mononucleósico. Dentro del estudio resultó una IgM para VEB positiva. Persistió con fiebre, odinofagia, y se agregaron adenopatías cervicales dolorosas, sin respuesta a fármacos antiinflamatorios. Se realizó una TC cervical con contraste que evidenció un flegmón periamigdalino (Figura 3). Se solicitó una serología para 


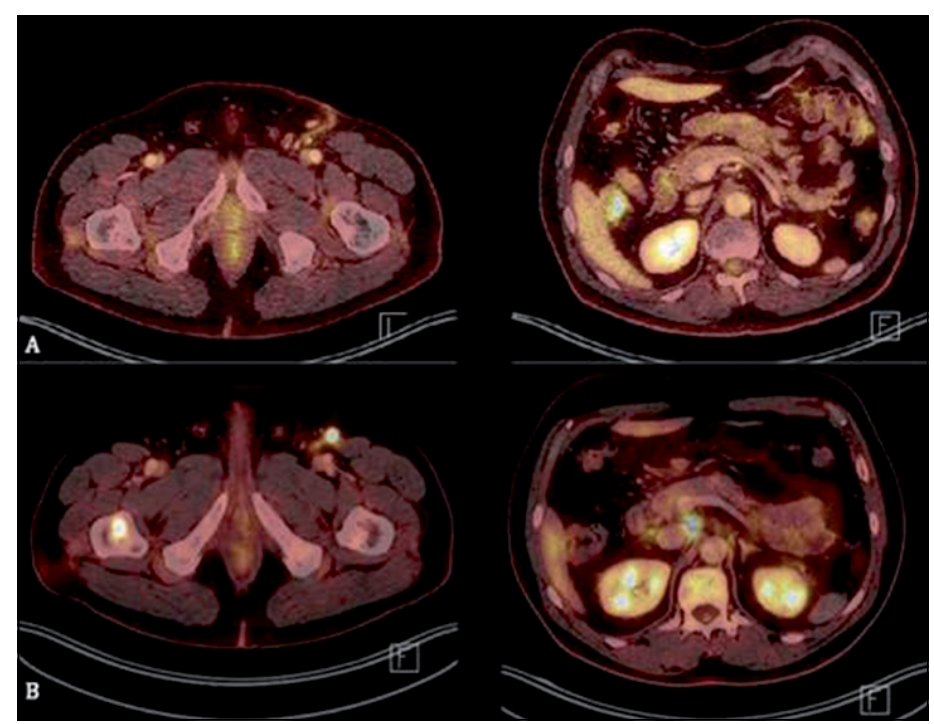

Figura 1. A) PET/CT con 18-FDG, corte transversal. En la imagen de la derecha, se identifican áreas hipermetabólicas en el extremo proximal de fémur derecho y en el ganglio inguinal izquierdo. En la imagen de la izquierda, se logra visualizar adenopatías hipermetabólicas retroperitoneales; B) PET/CT con 18-FDG, corte transversal. Control al mes posterior a tratamiento antimicrobiano. Al comparar con el estudio previo, se identifica desaparición de las lesiones hipermetabólicas en el extremo proximal del fémur derecho, adenopatías inguinales y retroperitoneales.
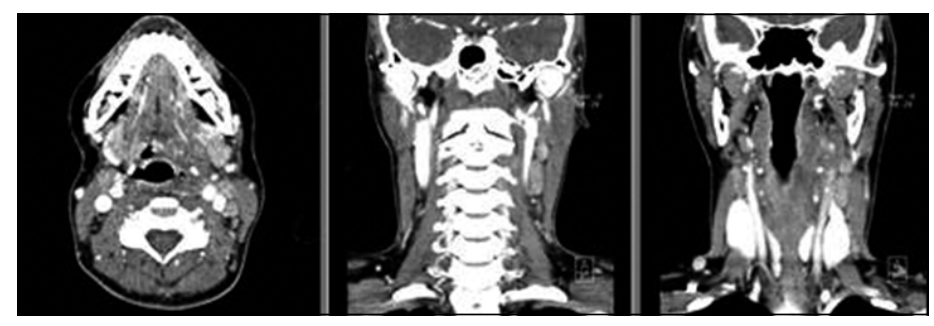

Figura 3. TC de cuello con contraste, cortes transversales y coronales. Se identifica área de conglomerado de adenopatías cervicales.

B. henselae que fue positiva (1:512), por lo que se recibió terapia con azitromicina, presentando una remisión clínica y de las lesiones en un control imagenológico.

\section{Discusión}

El diagnóstico diferencial de las linfadenopatías requiere la búsqueda de enfermedades infecciosas, tanto bacterianas (incluyendo tuberculosis) y virales, neoplásicas y enfermedades autoinmunes, entre otras ${ }^{6-10}$. El apoyo diagnóstico con imágenes deben ser parte del estudio inicial de esta patología. Las características de las adenopatías y su distribución pueden ayudar al diagnóstico, además de localizar el mejor acceso de punción para el estudio histológico.

En el caso de la enfermedad por arañazo de gato se puede objetivar, a través de la ecografía, linfonodos superficiales aumentados de tamaño, hipoecogénicos e hipervascularizados. La TC aporta en el diagnóstico de

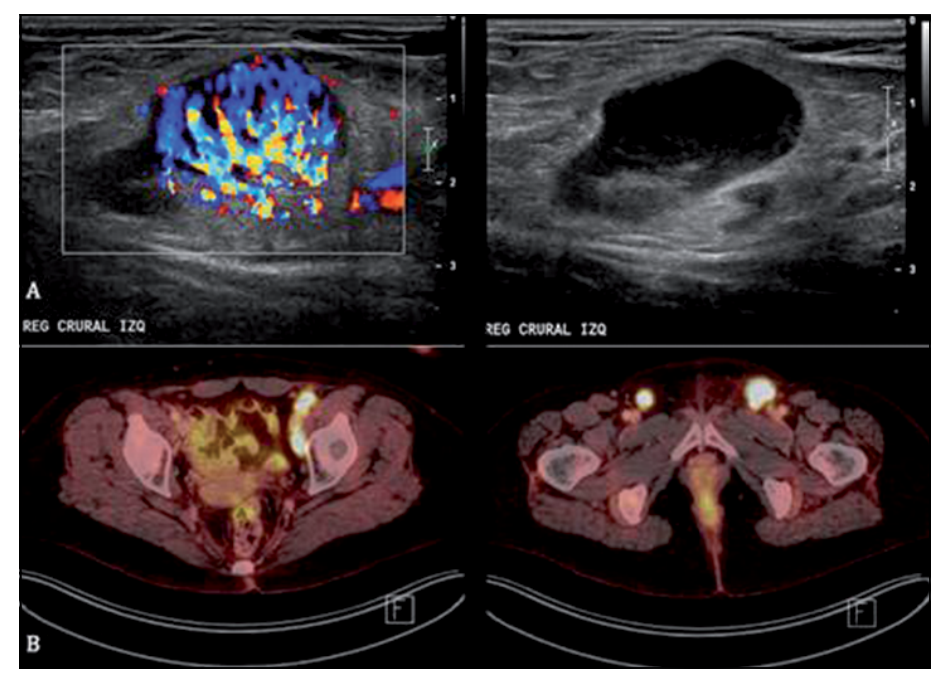

Figura 2. A) Ultrasonografía inguinal. Se observa linfonodo aumentado de tamaño, hipoecogénico y hipervascularizado de $3 \times 1,8 \mathrm{~cm}$, rodeado de tejido adiposo ecogénico de aspecto edematoso, reconociéndose además, algunos pequeños linfonodos de similares características en su vecindad; B) PET/CT con 18-FDG, corte transversal. Se visualizan conglomerado de adenopatías hipermetabólicas inguinales bilaterales y en las cadenas ilíaca interna y externa izquierda.

adenopatías profundas, difíciles de estudiar por ecografía, como las intraabdominales. Pueden observarse linfonodos aumentados de tamaño, con necrosis central y edema en el área de drenaje linfático cercano al sitio de inoculación, descartando así otros diagnósticos diferenciales.

En la resonancia magnética las adenopatías se observan como estructuras heterogéneas rodeadas de edema, caracterizadas por masas hipointensas en imágenes $\mathrm{T} 1$ e hiperintensas en imágenes $\mathrm{T} 2$, con realce periférico al contraste con gadolinio, mejorando la caracterización de las adenopatías con respecto a la $\mathrm{TC}^{11}$.

$\mathrm{La} \mathrm{PET} / \mathrm{CT}$ es una herramienta diagnóstica con un buen rendimiento para enfermedades de alto índice de metabólico, que junto a la combinación de la TC, puede definir la anatomía exacta de un foco de alta actividad metabólica, disminuyendo las tasas de falsos positivos o negativos. La evaluación de linfonodos mejora en forma considerable, independiente de su tamaño y localización, evidenciándolos en focos ocultos o en estructuras no distensibles como el hueso. Muestra un índice de captación aumentado en estructuras de alto índice metabólico antes de presentar cambios estructurales, permitiendo un diagnóstico precoz y mejorando el pronóstico de enfermedades. Además, permite realizar el seguimiento de las lesiones, logrando así evaluar la respuesta terapéutica precoz, confirmando la enfermedad, descartando los diagnósticos diferenciales y evitando procedimientos y hospitalizaciones innecesarias. Dentro de sus desventajas destaca su alto costo e índice de radiación, dificultando su uso en, por ejemplo, pacientes pediátricos ${ }^{12}$.

En la actualidad, han aumentado las recomendaciones de esta técnica para el estudio de enfermedades neoplásicas, inflamatorias, autoinmunes e infecciosas. Sin embargo, su interpretación para el diagnóstico diferencial debe integrar además los antecedentes clínicos y epidemiológicos del paciente. 


\section{Resumen}

La infección por Bartonella henselae es una zoonosis frecuente transmitida por el gato doméstico. En la mayoría de los casos se presenta con una linfadenitis regional. La búsqueda y caracterización de los ganglios linfáticos por imagenología puede ser útil en el diagnóstico diferencial, con la ventaja de ser un método no invasor. En la actualidad, nuevas técnicas de diagnóstico por imagen han mejorado la detección y caracterización de las adenopatías, tal es el caso de la tomografía por emisión de positrones (PET/ CT) que permite la evaluación de ganglios linfáticos hipermetabólicos, de manera independiente del crecimiento individual de cada ganglio linfático. Se revisan tres casos de enfermedad por arañazo de gato y sus estudios imagenológicos respectivos.

\section{Referencias bibliográficas}

1.- Cornejo W, Vizcarra H. Bartonella henselae: nuevo patógeno en humanos. An Fac Med 1999; 60: 281-92.

2.- Ferrés M, Abarca K, Godoy P, García P, Palavecino E, Méndez G. Presencia de Bartonella henselae en gatos: cuantificación del reservorio natural y riesgo de exposición humana de esta zoonosis en Chile. Rev Med Chile 2005; 133: 1465-71.

3.- Florin T A, Zaoutis T E, Zaoutis L B. Beyond cat scratch disease: widening spectrum of Bartonella henselae infection. Pediatrics 2008; 121: e1413-25.

4.- Rozmanic V, Banac S, Miletic D, Manestar K, Kamber S, Paparic S. Role of magnetic resonance imaging and scintigraphy in the diagnosis and followup of osteomyelitis in cat-scratch disease. J Paediatr Child Health 2007; 43: 568-70.

5.- Einstein D M, Singer A A, Chilcote W A, Desai R K. Abdominal lymphadenopathy: spectrum of CT findings. Radiographics 1991; 11: 457-72.

6.- Martínez R, Reyes P, Schiappacasse G, Cruz F, Solar A. Tuberculosis ganglionar retroperitoneal y mesentérica: caso clínico. Rev Chil Radiol 2004; 10: 126-8.

7.- Harisinghani M G, McLoud T C, Shepard J A, Ko J P, Shroff M M, Mueller P R. Tuberculosis from head to toe. Radiographics 2000; 20: 449-70.

8.- Riquelme V, García C. Estudios de imágenes en el diagnóstico precoz de leucemia en pediatría. Rev Chil Radiol 2012; 18: 24-9.

9.- Suárez T, García V, Estrada T, Acosta F. Imágenes en tuberculosis abdominal. Rev Colomb Radiol 2010; 21: 3025-35.

10.- Abarca K, Winter M, Marsac D, Palma C, Contreras A, Ferrés M. Exactitud y utilidad diagnóstica de la IgM en infecciones por Bartonella henselae. Rev Chilena Infectol 2013; 30: 125-8.

11.- Wang C W, Chang W C, Chao T K, Liu C C, Huang G S. Computed tomography and magnetic resonance imaging of cat-scratch disease: a report of two cases. Clin Imaging 2009; 33: 318-21.

12.- González P. Oncología: evaluación con tomografía computarizada con emisión de positrones. Medwave 2010; 10 (6): e4593. 